\title{
Economic Incentives to Improve Water Quality in Agricultural Landscapes: Some New Variations on Old Ideas
}

\begin{abstract}
Catherine L. Kling
Agricultural nutrients and other emissions remain a primary source of water quality degradation in much of the nation. Many such sources are classified as "nonpoint" sources under the Clean Water Act and are therefore exempt from most federal regulations and enforceable standards. In addition, many agricultural nonpoint source emissions are difficult to measure and the damages that result from them depend on the amount that is transported to the waterways. Nutrient runoff (particularly nitrogen and phosphorous) from intensive row crop agriculture in much of the cornbelt exemplifies these issues. Both the lack of enforceable standards and the physical characteristics of nutrient fate and transport make the design of efficient policy challenging, as witnessed by the lack of significant progress over the last several decades.
\end{abstract}

Economists have written extensively about water quality problem including careful theoretical models capturing the essence of the nonpoint source problem (Griffin and Bromley 1982; Shortle and Dunn 1986), the difficulties associated with policy design (Segerson 1988; Malik 1993; Hung and Shaw 2005), and a variety of empirical work helping to understand cost-effective options (Khanna, Yang, and Farnsworth 2003; Rabotyagov et al. 2010). In this paper, I stand heavily on the back of these giants and

Catherine Kling is Professor of Economics at Iowa State University. Financial support from the U.S. Environmental Protection Agency under their targeted watersheds grant program, the U.S.D.A. Conservation Effects Assessment Program, and CSREES is gratefully acknowledged. 
begin by summarizing and restating many of these "old" ideas, putting them in the context of the federal policy environment and pollution conditions associated with nutrient emissions from agriculture. I hope that this effort will, in a short space, give readers a flavor of the challenges that the characteristics of nonpoint source emissions create for efficient policy design.

My aim in the bulk of this paper is motivated by Voltaire's oft-quoted passage which translates roughly from the French as "the perfect is the enemy of the good." In the context of agricultural sources of water quality problems, I suggest that there are many proxies, models, and second-best instruments that could be relied upon to design and implement policy, even in the presence of the significant uncertainties that abound in nonpoint source issues. These "good" instruments are not perfect, but by relying on them we may be able to design and implement policy that makes progress in meeting society's water quality goals and improves social welfare in the process.

Thus, the two main goals of this paper are to 1) introduce readers to some of the key issues in agricultural nonpoint source water quality concerns and 2) raise and discuss the question of whether observable proxies can be efficiently used to support implementation of water quality improvement using economic incentives. In support of this query, I suggest some "new" variations on policy design based on proxies (specifically using a point system for abatement actions) and discuss how such policies might be designed with the aid of watershed based water quality models and evolutionary algorithms. Finally, a case study for the Boone River Watershed in central Iowa is used to demonstrate some of the ideas discussed. 


\section{Water quality and agriculture: A Snapshot of current conditions}

To set the stage, I begin with a brief overview of the current state of water quality in the

U.S. with a focus on problems attributable largely to agricultural sources. Several recent surveys provide consistent nationwide measures of the state of the nation's lakes, wadeable streams, and coastal zones. The 2007 National Lakes Assessment provides a representative view of the water quality of natural and man-made lakes and reservoirs (www.epa.gov/lakessurvey ). Data collected include water quality variables (nutrients, dissolved oxygen and algal density) as well as biological indicators, recreational indicators and physical habitat indicators. Lakes were classified based on their biological health with about $56 \%$ of lakes being classified as in "good" condition, about $21 \%$ in "fair" condition, with the remaining $22 \%$ identified as "poor." Poor lakeshore habitat is present in about $36 \%$ of the lakes and nutrients are at high levels in about $20 \%$, a condition associated with poor biological health.

The Wadeable Streams Assessment (www.epa.gov/owow/streamsurvey) was completed in 2004. Like the lakes assessment, a key focus was to evaluate the biological condition of streams while also collecting data on physical and chemical stressors of the system. Streams were also categorized into groups with $28 \%$ falling into the "good" condition category, $25 \%$ were considered in "fair" condition, and $42 \%$ were "poor." Despite differences in conditions across the country, nutrients, streambed sediment and riparian disturbances were the major stressors in all regions. The National Coastal Condition Report III (www.epa.gov/owow/oceans/nccr/ ) was the third assessment of coastal waterways (including the Great Lakes) and provided rankings by region of the 
country. The report concludes that the overall condition of the coastal waters is "fair" which they based on separately assessing five indicators of ecological condition.

Data from a nationwide survey of probabilistic sampling that uses consistent methods to sample and report the quality of either wetlands or rivers is not yet available. ${ }^{1}$ However, states are required under the Clean Water Act to provide the EPA with a summary of water quality conditions every two years. The latest National Summary of State Information (http://www.epa.gov/waters/ir/) indicates that of the roughly $26 \%$ of rivers and streams that have been assessed nationwide, $50 \%$ have been identified as having inadequate water quality to fully support the uses for which they have been designated (such as fishing, recreation, etc.). Thus, nearly half of a million stream miles have been identified as "impaired." Wetlands are also reported on in the statewide surveys, but very few total wetland acres have been assessed (about 2\%) of which about $35 \%$ were found to be impaired. Based on the same data, agriculture is identified as the cause of about $22 \%$ of the threatened or impaired river miles nationwide and is the single highest source (with "unknown" the next most prevalent category). Agriculture is also reported as the number one source of impairment of wetlands accounting for over half of the impaired acres nationwide.

The causes of water quality impairment in our nation are highly varied. Agricultural nonpoint sources are not the only significant contributor, but there are many locations and impairments for which meaningful improvements in water quality are not viable without addressing agricultural contributions. Many nonagricultural sources have 
already reduced their contributions; thus agriculture may be a source of relatively costeffective improvement.

\section{Some Old Ideas: Nonpoint Source Water Quality Pollution and their Spatial Nature}

The characteristics of the process by which agricultural sources contribute to poor water quality creates difficult challenges for the design and use of policy instruments generally, and economic incentives in particular. The nature of these contributions has been carefully modeled and discussed (see Shortle and Horan 2001 or Olmstead 2010 for excellent surveys). A simple model can help highlight the issues.

A firm (producer) located in watershed $\mathrm{j}(\mathrm{j}=1, \ldots, \mathrm{J})$ maximizes profits $\left(\pi_{\mathrm{ij}}\right)$

$$
\pi_{i j}=p y_{i j}\left(x_{i j}, a_{i j} \mid L_{i j}\right)-c\left(y_{i j}, a_{i j} \mid L_{i j}\right), \quad i=1, \ldots, I_{j}
$$

where $p$ represents output price, $\mathrm{y}_{\mathrm{ij}}(\cdot)$ is the production function associated with firm $\mathrm{i}$ located in watershed $\mathrm{j}, x_{\mathrm{ij}}$ is the vector of inputs into production, $a_{\mathrm{ij}}$ is the vector of abatement activities (conservation actions) that a firm undertakes, $\mathrm{c}(\cdot)$ is the cost function, $L_{\mathrm{ij}}$ is a vector representing physical land characteristics such as soil type, slope, and weather, and $\mathrm{I}_{\mathrm{j}}$ indicates the number of producers in the $\mathrm{j}^{\text {th }}$ watershed. The firm generates emissions as a side effect of its production,

$$
e_{i j}=e_{i j}\left(x_{i j}, a_{i j} \mid L_{i j}, \varepsilon_{i j}\right)
$$

where $\varepsilon_{\mathrm{ij}}$ is a stochastic term that represents weather or other random elements in the physical system. For concreteness, call these emissions "nutrients" and note that equation (2) describes edge-of-field nutrient emissions: the amount of nutrients leaving the field. Externality damages occur when these nutrients enter waterways (rivers and lakes) and move downstream. The amount of nutrients that reach the water bodies of 
interest depends on the spatial distribution of land use and emissions in the watershed, as well as on random weather. Thus, the ambient water quality in the rivers at the outlet of watershed "j" can be written

$$
W Q_{j}=W Q_{j}\left(e_{1 j}\left(x_{1 j}, a_{1 j} \mid L_{1 j}, \varepsilon_{1 j}\right), \ldots, e_{I, j}\left(x_{I, j}, a_{1 j} \mid L_{I, j}, \varepsilon_{l, j}\right)\right), \quad j=1, \ldots, J, .
$$

Two features of the externality described in equations (1) - (3) are noteworthy: the nonpoint source nature of the emissions source (Segerson 1988; Shortle and Dunn 1982), and their spatial characteristics (Montgomery 1972; Baumol and Oates 1987). The definition of "nonpoint" varies among authors, but one that would seem to encompass the notion of most is that the emissions that ultimately generate damage to the externality are very costly to trace to their precise source. Reasons cited for the lack of traceability include complexity of the production relationship between inputs and the biophysical processes (such as nutrient cycling and the movement of surface water) and the importance that weather (precipitation and storm events) has on the fate and transport of emissions. The simple model represents the nonpoint nature of the externality via the error term and potential complexity of the processes described generally by equation (3). The result of this identifiability issue is that a first best policy instrument based on the firm's contributions to damage will be difficult or impossible to implement.

The spatial nature of agricultural emissions refers to the fact that the location of emissions within a watershed may affect the magnitude of the damages associated with those emissions (equation 3$)^{2}$. Emission sources located further from water bodies or further from the endpoint of a watershed may mean that fewer nutrients enter the receiving body. The degree of this attenuation will depend on many physical features, 
including slope, soils, vegetation, and weather. Further complicating this problem in the case of agricultural emission is the fact that the degree of this attenuation can depend on land use choices made by others in watershed. As an example, imagine the amount of nutrients that leave a field " $\mathrm{A}$ " and enter a stream under two different landscape configurations. In one case imagine that a field " $\mathrm{B}$ " planted in perennial grasses lies between field A and the waterway. In the other case, imagine that field B is planted in conventionally tilled row crops. For any given amount of nutrient runoff from field A, it is likely that more will enter the stream if field B is highly tilled than if it is planted in perennial grasses. Thus, the marginal damages that A's activity has depends on the action of a farmer in another location - farmer B. This situation has been referred to as nonconstant diffusion coefficients or endogenous coefficients (Khanna, Yang, and Farnsworth, 2003).

\section{Some More Old Ideas: History and the Existing Policy Milieu}

The dominant federal statutes relating to water quality emissions are contained in the Clean Water Act Amendments (CWA) of 1972. Under this Act, point sources (such as wastewater treatment plants, factories, and CAFOs) are required to obtain permits for their discharges. Permit levels for point sources are based on the "best available technology" that is economically achievable. Nutrients, pesticides, sediment, and other runoff from row crop or specialty crop agriculture, forestry, and septic systems are specifically exempt from the permitting system.

Water quality standards are also an integral part of the CWA. However, the term "standard" bears further discussion as its usage in the CWA is not akin to the quantity 
instrument that environmental economists commonly analyze. Specifically, a water quality standard (http://www.epa.gov/lawsregs/laws/index.html\#env) is comprised of several components including a "designated use" and "criteria" to determine whether the quality of the water supports the designated use. Of key importance for economists interested in policy design is that these "standards" do not translate into responsibility on nonpoint polluters to reduce their pollution levels. Point sources must have permits to cover their emissions and thus do face binding standards, but nonpoint sources face no binding legal requirements under the $\mathrm{CWA}^{3}$

Does this mean that nonpoint sources of water pollution have not been addressed at all in the policy environment? Not at all --- a large suite of federal and state programs have developed and been revised over the last two decades to provide funding and support for voluntary programs. In addition to funds from EPA's 319 program, federal programs such as the Conservation Reserve Program, the Environmental Quality Improvement Program, the Conservation Security Program, and the Wetlands Reserve Program have provided substantial cost share and direct payments for conservation actions on agricultural lands to address nonpoint source pollution.

A more recent focus of policy is water quality trading. Both EPA and USDA (http://wvwri.nrcce.wvu.edu/programs/pwqb/pdf/mou061013.pdf ) have embraced the concept and have produced training materials and decision support tools to aid implementation. Since point sources face a cap (via the permitting process), trading programs based on point sources have been initiated with trades occurring between point sources and between point and nonpoint sources (where nonpoint source reductions can 
earn offset credits for purchase and use by point sources). However, few point/nonpoint trades have been made, hindered in part by inflexible trading rules and requirements that point sources prove that equivalent reductions are achieved from nonpoint sources (see King 2005 for a discussion of limitations to current programs).

Probably most problematic for purposes of achieving water quality gains in the context of a trading program is that in many watersheds, a large majority of nutrients originate from agricultural nonpoint sources; hence, even draconian caps on point sources could not achieve the desired water quality improvements. Ribaudo et al. (2008) provide a summary of nitrogen impaired waters across the U.S. that succinctly makes this point. They note that there are over 700 such watersheds that could, in theory, support the formation of a water quality trading program focused on nitrogen. However in $68 \%$ of those watersheds, agriculture contributes $90 \%$ or more of the total loads. Thus, even if requirements were placed on point sources to reduce their emissions to zero, the maximum nitrogen reductions achievable would be less than $10 \%$.

\section{New Variations: Using Proxies for Policy and an Abatement Action Permit System}

At first blush, the inability to measure emissions at their source would seem to prevent the setting of a cap that could form the basis for a trading program, or even an enforceable command-and-control style regulatory paradigm. However, there are cases where emissions, though formally classified as nonpoint sources under the CWA, are either observable or close proxies such as input use, land management or abatement actions that reduce emissions are directly observable (see Stephenson, Norris, and Shabman 1998 for more discussion especially concerning the direct observability of 
emissions). Further, the existence of watershed based water quality models can provide useful guidance regarding the most important locations within a watershed to implement emission reduction actions and which subwatersheds are the most important to target.

An example of direct observability is the tile drained acres of the Midwest where these tiles drain land via pipes, sometimes directly into waterways. These pipes are observable and could be monitored (at a cost) for their nutrient concentrations and water flow. Second, in cases where emissions from a field are not observable, there are many inputs and abatement actions that are observable, including for example, the use of reduced tillage practices, the implementation of grassed waterways, buffer strips, contour farming, the fencing of cattle out of streams, placement of wetlands, etc. Further, both emissions and their proxies will be increasingly observable as technology improves (remote sensing may be a game changer). Improved biophysical models that can be used to describe the in-field and watershed level fate and transport of emissions are also increasingly available as are the data to populate them.

Thus, while the direct lack of observability of emissions from the source may limit the ability to apply first best policy instruments, there are observable actions that are close proxies for emissions, and there are models that can approximate those relationships in lieu of observable proxies. If emissions are often not directly observable, but proxies for them are, why not design policy around that which are observable? As an alternative to a cap on emissions or ambient concentrations of emissions, consider a permit system where the cap is based on abatement actions. Under this Abatement Action Permit System (AAPS), agricultural producers would face requirements to undertake 
abatement actions, such as adopting one or several conservation practices on part or all of their land (in this case, a "cap" is actually a floor defining the minimum number of credits required).

There are many ways such a system could work, but one way these requirements could be operationalized is via a point-based system where conservation practices are assigned a point value based on their effectiveness at reducing emissions from a field. The points associated with each practice could vary by characteristics of the field, location in the watershed or other variable. Each producer would be required to have an average number of points per acre to satisfy their requirement. This requirement could be met by having adequate abatement actions on each field to meet the requirement field-byfield, or conservation practices with higher points could be placed on some acres with no practices elsewhere on fields operated by a producer as long as the total number of points accumulated satisfies the aggregate requirement. In addition, farms could trade points so that the lowest cost providers of effective abatement actions could be used most extensively.

\section{An Abatement Action Permit System (AAPS) based on points}

While the details of such a system would require careful consideration, in the following I describe a few possible parameters of such a system.

1. Assign each conservation practice/land use a point value based on the effectiveness of the practice. These point values could be chosen based on expert opinion and informed by biophysical models. When choosing practices and their associated point values, it will be important to consider the degree to which the practices are observable, 
this could be used as a factor in determining which practices to give credits to and how many credits the practice earns. Point values for a given practice could be conditional on its location within a field and on the soil type or other physical features, i.e., the same practice placed on a highly sloped field might earn more points than that practice placed on flat terrain. In some cases it may make sense for combinations of practices to be assigned points that are not the simple sum of their separate practices (i.e., adoption of both no till farming and grassed waterways might not be assigned the sum of the two point values if separately implemented). Thus, if these two practices simultaneously employed exhibit increasing returns in nutrient reduction, a higher point value than their simple sum should be assigned to their joint implementation.

2. Choose a total amount of points for the watershed and allocate those points among fields. Here there is considerable latitude for the implementing agency. An equal number of points per acre would be one obvious allocation, but allocations could also be based on previous conservation history --- in this case, higher point allocations indicate a higher obligation for abatement action so lower point requirements would be the way to reward "good actors." Farmers who have previously adopted conservation practices could be credited for those actions in this setting.

3. Allow farmers to buy/sell points among each other using either one-for-one trades across the watershed, one-for-one trades within a sub watershed, or based on trading ratios used for spatially disparate farms. The implementing agency would want to consider the potential tradeoffs between having larger zones and thereby more participants in the market with less spatially efficient trading patterns. The agency might 
also want to consider the complexity and possible transaction costs associated with non one-for-one trading ratios. The magnitude of these tradeoffs are likely to be watershed specific.

4. Implement an enforcement mechanism. Fines or traditional penalties could be used. Alternatively, the conservation compliance provisions associated with farm program payments could be used as the enforcement mechanism. The efficacy of this approach requires, as in the current situation, that the value of farm program payments be large enough to induce adequate compliance.

5. Include options to encourage innovation. An important part of any incentive based program is to encourage innovation. This could be incorporated into the AAPS by including provisions that allow farmers to test new abatement options so that if they can demonstrate that new methods are effective, they can be assigned points and brought into the system. This provides incentive for the development of more cost effective ways to meet conservation goals.

6. Include explicit mechanisms for adaptive management: Despite many years of study, much is still unknown about the efficacy of abatement activities on the landscape. Thus, any approach policy should provide the opportunity for changes in the system as experience and new information become available. The value of flexibility must be weighed against the benefit that decision makers accrue from certainty in the regulatory environment for planning horizons. In designing the AAPS, it may be desirable to guarantee that the details will be unchanged for a given time horizon (i.e., specific point allocations and permit values), say 5-10 years, after which monitoring and modeling data 
could be used to revise the point system and/or allocation based on the degree to which water quality has or has not improved.

To implement an AAPS, an agency must assign points to a practice and decide whether to vary those points by location and/or land characteristic. In the ideal case, the agency would know where the best location for practices is and use that information to construct the point system. Before turning to a case study, I describe in the next section the "new" tool of evolutionary algorithms which is increasingly being used in water quality modeling and other complex problems (see Srivastava, et al. 2002; Veith, Wolfe, and Heatwole 2003; and Arabi, Govindaraju, and Hantush 2006 for early examples). In the case study, this tool is applied and the manner in which it might be used to support the design of an AAPS or other policy is described.

\section{Another Variation: Water Quality Models and Evolutionary Algorithms}

There are multiple watershed based hydrology and water quality models designed to simulate the effects that different land uses (including conservation actions) have on instream water quality. The value of these models is that they can simulate the effect of any combination of land uses on ambient water quality (typically measured at the exit point of the watershed). These models represent the spatial interdependence of the effectiveness of abatement actions. While valuable for the more realistic representation of the nonlinear fate and transport of nutrients and sediments across the landscape, the spatial interdependence makes the optimization problem of identifying the least cost solution extremely difficult. 
A "brute-force" approach would be to evaluate all possible combinations of the placement of abatement actions by computing the costs and running the watershed model to predict the water quality. From the universe of solutions, the most desirable option could be selected. However, as Rabotyagov (2007) and others have noted, the solution set quickly becomes unwieldy; with only 12 fields and 4 mutually exclusive abatement actions, there are $4^{12}$ options which exceeds 16 million. Watersheds have hundreds of fields, meaning that even with high powered computing, brute force is not a viable approach.

Fortunately, evolutionary algorithms (EA), powerful optimization algorithms that draw on the logic of evolution to search intelligently across large regions and characterize solutions to complex problems, were developed for just these types of problems. Following Rabotyagov (2007) and Rabotyagov et al. (2010) an EA is used to represent a Pareto frontier showing the least cost combination of options for achieving reductions in two nutrients. Numerous single and multiobjective algorithms are available and an extensive literature exists (Osyczka 2002). Here, I describe the improved version of the Strength Pareto Evolutionary Algorithm --- SPEA-2 (Zitzler, Laumanns, and Thiele 2001) which is implemented in the case study that follows. Rather than explain the algorithm in general terms, I describe the basic logic in the context of the application at hand: identifying an optimal set and location of abatement activities when the objective is to minimize the cost of abatement and the ambient concentrations of two nutrients: phosphorous and nitrogen. 
In brief, the algorithm begins with a population (size N) of "individuals" which are possible solutions. In this context, an individual is a watershed configuration, a mapping of a specific set of land use/conservation practices to each field in the watershed. The cost of those conservation practices is computed and the water quality effects predicted via a water quality model. The next step is to pareto compare the cost and water quality to select the watershed configurations that are not pareto dominated. By repeatedly creating new watershed configurations based on the most successful previous configurations, and undertaking additional pareto comparisons, a good approximation to the pareto frontier can be derived. The following steps describe the basic components of the algorithm (again, written in the context of watershed comparisons).

Step 1: Generate an Initial Population

A population is a set of individuals (watershed configurations). These can be created by random assignment of an abatement action to each field or nonrandom assignments can be employed. In the case study here, 40 individuals are initially created. This initial population of individuals represents the first "generation" of possible solutions.

Step 2: Run a watershed water quality model, compute costs

In this step, the metrics for comparing each individual in the potential solution set are constructed. We compute the cost of each watershed configuration's set of abatement actions and run the watershed water quality model to predict reductions in nitrogen and phosphorous. Thus, in the first generation of the algorithm, there are 40 individuals, each 
comprised of a different set and allocation of abatement actions across the watershed and each associated with a given cost and phosphorous and nitrogen level.

Step 3: Identify Best Individuals

Based on the cost and pollution estimates from the previous stage, each individual is pareto compared to all others. Individual "A" pareto dominates another individual if A costs less for at least as much pollution improvement or achieves more improvement for the same or less cost. Once the pareto comparison is completed, the strength $(\mathrm{S})$ of each individual is defined as the number of others that this individual dominates. From the strength values are computed the raw fitness $(\mathrm{F})$, defined as the sum of the strengths all individuals that dominate the individual in question. The lower the value of raw fitness, the better. When an individual is on the pareto frontier, it is dominated by no other individuals and thus its raw fitness value is zero.

In addition to being at or near the pareto frontier, there are other attributes of an individual that make it potentially desirable, specifically its distance from other pareto nondominated individuals. Thus, SPEA2 contains a density measure that is a variation of the kth nearest neighbor computation ${ }^{4}$ and the final fitness of an individual is defined as the sum of the raw fitness and the density score: $F=D+R$.

Step 4: End if stopping rule is met

The algorithm can be set to run a given number of generations, or another stopping rule can be applied. At this point, the set of nondominated individuals forms the pareto frontier. These individuals are identified and potentially analyzed further. Step 5: Choose parents 
The most fit individuals from step 3 are selected via a binary tournament with replacement. Two individuals are randomly chosen and the one with the highest fitness score is placed into the mating pool.

Step 6: Create Offspring

New individuals are created from the individuals in the mating pool. First, a process of crossover is used where two parents are randomly selected and their "genes" are crossed, that is, some of the set of abatement actions in one individual are chosen for the child and the remainder come from the second parent. Finally, an occasional "mutation" is applied where one of the abatement actions assigned to a field is randomly changed. Once a complete set of new individuals is created, return to step 1.

Next, I turn to an empirical application where an evolutionary algorithm is used to identify a pareto frontier between costs and water quality. While the direct link to a point-based trading program is not described here, the frontier directly relates the adoption of practices to ambient water quality and costs and thus provides direct information that could support the design of a point-based AAPS.

\section{Application to the Boone River Watershed}

Using a finely detailed and spatially explicit data set on agricultural land uses in the Boone River Watershed in north central Iowa, a pareto frontier is constructed that represents the tradeoffs between abatement costs and water quality. The frontier can be used to identify the set of conservation practices (and their location in the watershed) that achieves the least cost approach of achieving a given water quality goal. Alternately, it can identify the set that achieves the greatest nutrient reductions for a given expenditure. 
The Boone River Watershed (see figure 1) covers nearly 600,000 acres in North Central Iowa, is heavily tile drained with few remaining wetlands, and is dominated by row crop agriculture. Maize and soybeans cover nearly $90 \%$ of the surface area. There are 128 confined animal feeding operations in the watershed, most of which are swine operations. From an environmental perspective, the Boone watershed discharges some of the highest level of nitrogen ads among Iowa watersheds. However, the Boone River which, runs through the center of watershed, has been identified as an area of freshwater biodiversity significance and has been identified as a priority area for conservation by The Nature Conservancy due to the vulnerability of its relatively un-degraded stream ecosystem. Likewise, the Iowa Department of Natural Resources has designated the Boone as a protected water area.

Detailed field-level data on land use and abatement actions were visually collected for each individual field (common land unit) for all agricultural land in the watershed in the spring of $2005 .^{5}$ This data was combined with detailed soil, topographic, and climate data at the field scale. Additionally data on the location of livestock operations, point sources, other land cover, water quality and flow were collected and combined to provide a baseline description of the watershed and environmental indicators (see Gassman (2008) for details). This data was also used to calibrate the Soil and Water Assessment Tool (SWAT; Arnold and Fohrer 2005), a watershed-based water quality model which divides the watershed into homogenous land use units, termed Hydrologic Response Units (HRUs). There are just over 2900 HRUs in the Boone model which is the key spatial unit of analysis. Nitrogen, phosphorous, and sediment loadings are routed 
from each HRU through the stream system to the watershed outlet. The model is designed to evaluate the effect of alternative land use scenarios on water quality and erosion.

Four abatement actions (conservation practices) were considered in constructing a pareto frontier: no till, reduced fertilizer (defined simply as a $10 \%$ reduction in fertilizer use), planting of cover crops, and land retirement (removing land from crop production and replanting native perennials). Several of these activities can be undertaken in combination. When all viable combinations are considered, there are eight possible land uses that include at least one abatement action plus conventional farming which results in nine possible choices for each field. The cost of each abatement action per field was estimated from a variety of sources. In some cases, such as land retirement and reduced fertilizer, the costs vary by field depending on the soil type and corn suitability rating. ${ }^{6}$ In the case of cover crops and no-till, a single cost estimate for each field in the watershed is applied ${ }^{7}$. The degree to which the aggregate costs accurately reflect the total willingness of producers in the watershed to adopt these practices depends, of course on the accuracy of the unit cost estimates. The results presented here should be considered as a starting point for additional sensitivity analysis rather than as the final word.

The evolutionary algorithm, SPEA- $2^{8}$, was applied using these cost estimates and the fully calibrated SWAT model using the data described above. Forty individuals were used to initialize the EA with nine of those individuals conforming to uniform assignment of the eight abatement actions or combinations thereof and the baseline (no new abatement actions). The remaining 31 individuals were generated by random assignment 
of the nine possible land uses to each field. A total of 132 generations were run. ${ }^{9}$ Each of these "individuals" represents a complete watershed configuration where the specific placement of abatement actions can be mapped.

As an example of the efficiency gains that the EA can suggest, consider table 1 which contains a summary of three individuals: two from the frontier and one of the initially seeded non-random individuals. The first row represents the initial seed where all fields in the watershed are assigned cover crops combined with reduced fertilizer. This assignment would cost over $\$ 15$ million and achieve about a $30 \%$ reduction in both $\mathrm{N}$ and $\mathrm{P}$. The second row represents an individual chosen from the frontier which achieves roughly the same reduction in $\mathrm{N}$, but achieves this reduction at about $20 \%$ of the cost (only about \$3 million) and achieves a larger P reduction as well --- nearly $45 \%$. The gains in cost and phosphorous measure the efficiency improvement associated with the selection of abatement actions indicated in the right hand side of the table. To achieve this gain, most land is placed into no-till with only a few locations placed in a combination of no-till and reduced fertilizer. The third row represents an individual that costs the same as the initial seed, but achieves far higher $\mathrm{N}$ and $\mathrm{P}$ reductions. In this case, some land (over 100 HRUs) is retired completely from production which is the most expensive and most effective abatement action with the remainder put in no-till and combined no-till, reduced fertilizer. Both of these individuals from the frontier demonstrate the significant efficiency gains that optimal placement can achieve.

By identifying the specific location for the practices identified in a chosen individual from the frontier, it is possible to visually identify patterns where practices are 
located (specific sub watersheds, distance to main waterways, etc. or to correlate the placement of those practices with land features such as soil type, corn suitability rating, slope or other land characteristic. These relationships can be used to develop implementation strategies for an incentive based system based on practices or as regulatory guides for command-and-control approaches. Figure 2 contains a map with the specific locations of the solution described in the third row of table 1 as an example.

Table 2 contains summary statistics for eight individuals from the frontier. The first row represents the individual that achieves at least a $10 \%$ reduction in both $\mathrm{N}$ and $\mathrm{P}$ at the lowest cost possible, the second row represents the individual that achieves at least a $20 \%$ reduction in both nutrients at lowest, and so on until an $80 \%$ is achieved. In a number of cases, the least expensive way to achieve the target percentage reduction in $\mathrm{N}$ actually over achieves the reduction in $\mathrm{P}$. This is a consequence of the fact that many of the abatement activities reduce both nutrients and that many of them were designed specifically for erosion control, which is closely related to phosphorous movement. Note also that for the first two target reductions there is no individual that achieves exactly 10 or $20 \%$ reductions so the closest is presented instead.

The second column reports the total cost for the associated nutrient reductions and the third puts that cost on a per/acre basis. Figure 3 plots the target reduction against the per acre cost, producing a supply curve of nutrient reductions. Recall that the horizontal axis represents the simultaneous reduction of both $\mathrm{N}$ and $\mathrm{P}^{10}$. Both the supply curve in figure 3 and the information in rable 2 highlight the increasing cost of nutrient reductions. To achieve a $10 \%$ reduction in nutrients, only about $\$ 2 /$ acre is needed and there appears 
to be relatively constant returns to scale up to $30 \%$ reduction which can be achieved at about $\$ 6.50 /$ acre. These reductions are optimally achieved by gradually increased the amount of acreage under no-till until this option is depleted. If higher reductions in nutrients are desired it becomes necessary to adopt more costly abatement activities via adding reduced fertilization to no-till and moving towards cover crops and some use of land retirement beginning with a 50\% reduction and continuing to $80 \%$ where almost all of the land must be retired to achieve the target.

In addition to representing the rising costs of meeting nutrient reductions, this analysis also points out that the optimal choice of abatement actions will depend on the target water quality level. At relatively low levels of reduction, much of the gains can be achieved with relatively low cost changes in tillage, but such options are not part of the solution set at the highest target levels.

\section{Final thoughts}

Water quality problems associated with agricultural activities in the United States are prevalent. Current federal policy is based on the Clean Water Act with its associated voluntary approach to nonpoint source agricultural water quality control and lack of enforceable standards on nonpoint sources. This approach places the property rights associated with water quality in the hands of generators of the externality. In this paper I have argued that new tools and a switch to a practice or "abatement action" focused policy may help us move towards improving social welfare. While not based on a perfect correspondence between emissions and ambient nutrient concentrations, such approaches might move us closer to meeting society's water quality improvement goals. 
There is precedence for acting to regulate environmental conditions when the correspondence between emissions and damages is imperfectly known. The $\mathrm{SO}_{2}$ trading program was initiated in the 1990 Clean Air Act Amendments as part of a tightening of emission standards on the electricity sector. The science at the time had established that emissions from coal fired power plants in the central and western U.S. were being transported eastward and ultimately deposited in the forests and lakes, damaging forests and ecosystems. Consequently, a tightened standard was adopted, an allocation of emissions was made, trading allowed, and the targeted forests are now recovering. This was accomplished without establishing the specific relationship between the emissions from each power plant and the location its emissions were deposited. Within agriculture, the precedent is even stronger. Numerous conservation programs including EQIP and the CRP have spent millions to cost share or provide direct payments for the adoption of practices without precise understanding of the relationship between the use of those practices and the ultimate social benefits.

I conclude with a hope that, regardless of the reader's reaction to the arguments and methods described in this paper, more agricultural and environmental economists will raise their pens in the study of these issues. Current policy and methods have not achieved the water quality goals set forth in the CWA in many agricultural watersheds. Applied economists have the set of tools and understanding of market institutions to find and support the implementation of better policy design. 


\section{References}

Arabi, M., R.S. Govindaraju, and M. M. Hantush. 2006. Cost-effective allocation of watershed management practices using a genetic algorithm. Water Resources Research (42), W10429.

Arnold, J.G., and N. Fohrer. 2005. Current capabilities and research opportunities in applied watershed modeling. Hydrological Processes 19: 563-572.

Baumol, D. and W. Oates. 1988. The Theory of Environmental Policy, 2nd edition. New York: Cambridge University Press.

Gassman, P.W. 2008. A Simulation Assessment of the Boone River Watershed: Baseline Calibration/Validation Results and Issues, and Future Research Needs. Ph.D. Dissertation, Iowa State University, Ames, Iowa.

Griffin, R. and D. Bromley. 1982. Agricultural Runoff as a Non-Point Externality A Theoretical Development," American J. of Agric. Economics, 64(3), pp.547-52.

Hung, M.F. and D. Shaw. 2005. "A Trading-Ratio System for Trading Water Pollution Discharge Permits. J. of Env. Economics and Management, 49(1), pp. 3-102.

Khanna, M.,W.H. Yang, and R. Farnsworth. 2003. Cost-effective Targeting of Land Retirement to Improve Water Quality with Endogenous Sediment Deposition Coefficient, American Journal of Agricultural Economics, 85(3), pp. 538-53.

King, D. 2005. Crunch Time for Water Quality Trading, Choices, 20(10): pp. 71-75.

Lankoski, J, E. Lichtenberg and M. Ollikainen. 2008. Point/Nonpoint Effluent Trading with Spatial Heterogeneity." American Journal of Agricultural Economics, 90(4), pp. 1044-58. 
Malik, A.S., D. Letson and S.R. Crutchfield. 1993. "Point Nonpoint-Source Trading of Pollution-Abatement - Choosing the Right Trading Ratio." American Journal of Agricultural Economics, 75(4), pp. 959-67.

Montgomery, D. 1972. "Markets in Licenses and Efficient Pollutioin Control Programs." Journal of Economic Theory, 5(3): pp. 395-418.

Olmstead, S. 2010. "The Economics of Water Quality,” Review of Environmental Economics and Policy, 4(1): pp 44-62.

Osyczka, A. 2002. Evolutionary algorithms for Single and Multicriteria Design Optimization, Physica-Verlag, New York, New York.

Rabotyagov, S. 2008 "Four Essays on Environmental Policy under Uncertainty with Applications to Water Quality and Carbon Sequestration." Ph.D. thesis, Department of Economics, Iowa State University.

Rabotyagov, S., T. Campbell, M. Jha, P. Gassman, S. Secchi, L. Kurkalova, H. Feng, J. Arnold, and C. Kling. 2010. "Least Cost Control of Agricultural Nutrient Contributions to the Gulf of Mexico Hypoxic Zone," Ecological Applications, in press.

Ribaudo, M., L. Hansen, D. Hellerstein, and C. Greene. 2008. "The Use of markets to Increase Private Investment in Environmental Stewardship,” Economic Research Service, Report No. 64, September.

Sawyer, J., E. Nafziger, G. Randall, L. Bundy, G. Rehm, B. Joern. 2006. Concepts and rational for regional nitrogen rate guidelines for corn. Iowa State University, 
Ames, Iowa. Available at:

http://extension.agron.iastate.edu/soilfertility/nrate.aspx. Accessed April 10, 2006.

Segerson, K. 1988. "Uncertainty and Incentives for Nonpoint Pollution-Control." Journal of Environmental Economics and Management, 15(1), pp. 87-98.

Shortle, J. and R. Dunn. 1986. “The Relative Efficiency of Agricultural Source WaterPollution Control Policies,” American Journal of Agricultural Economics, 68(3), pp. 668-677.

Shortle, J. and R. Horan. 2001،"The Economics of Nonpoint Pollution Control,” Journal of Economic Surveys, 15(3), pp. 255-289.

Srivastava, P., J.M. Hamlett, P.D. Robillard, and R.L. Day. 2002. Watershed optimization of best management practices using AnnAGNPS and a genetic algorithm. Water Resources Research 38(3): 1-14.

Stephenson, K, P. Norris, and L. Shabman. 1998. "Watershed-based Effluent Trading: the Nonpoint Source Challenge," Contemporary Economic Policy 16(4): 412-421.

Veith, T.L., M.L. Wolfe, and C.D. Heatwole. 2003. Development of optimization procedure for cost-effective BMP placement. Journal of the American Water Resources Association 39(6): 1331-1343

Zitzler, E., M. Laumanns, and L. Thiele. 2001. "SPEA2: Improving the Strength Pareto Evolutionary Algorithm,” TIK-Report 103, May 2001, Errata added September, 2001 


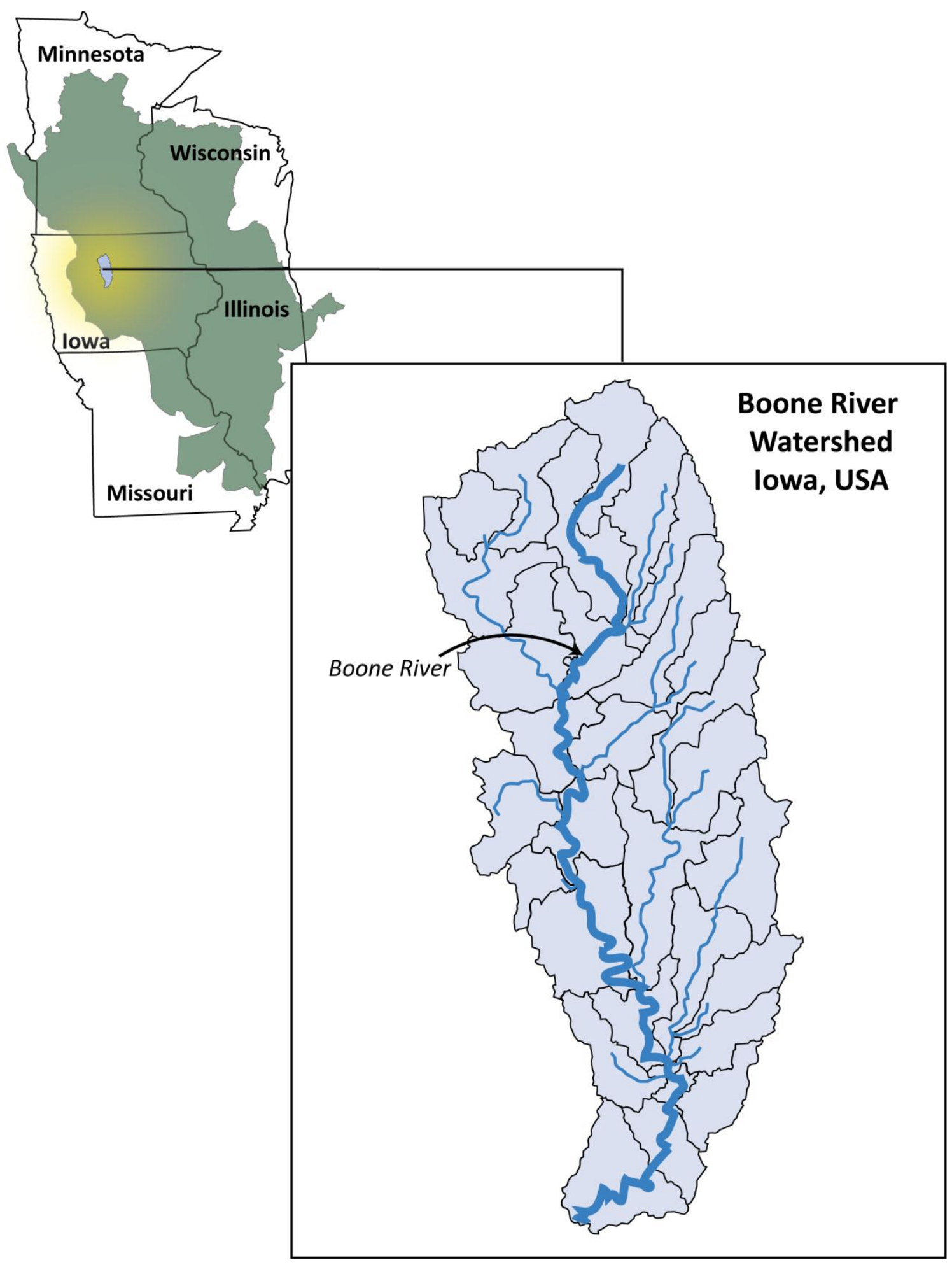

Figure 1: The Boone River watershed 


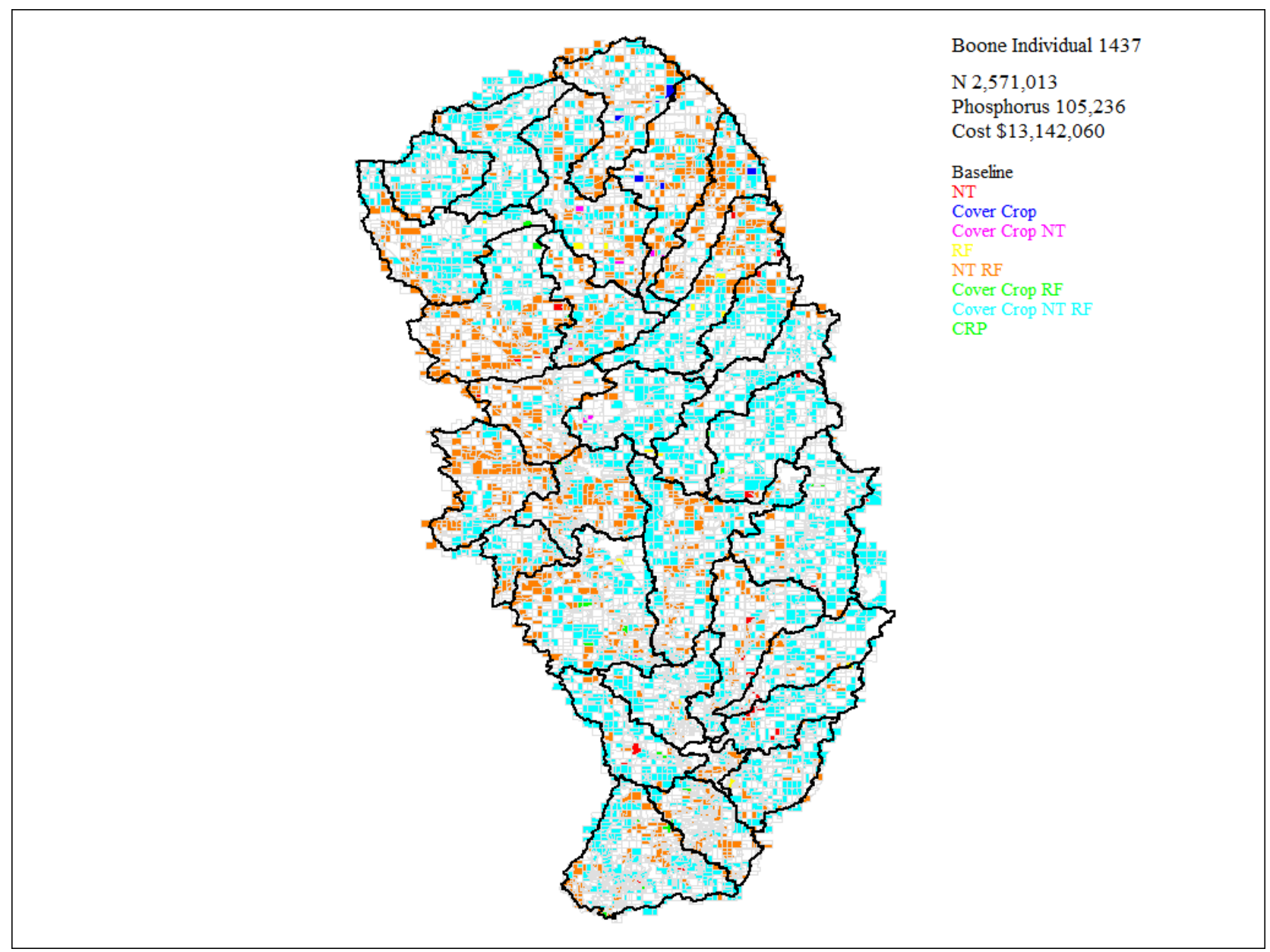

Figure 2: Watershed configuration of individual with same cost as cover crops and reduced fertilizer 


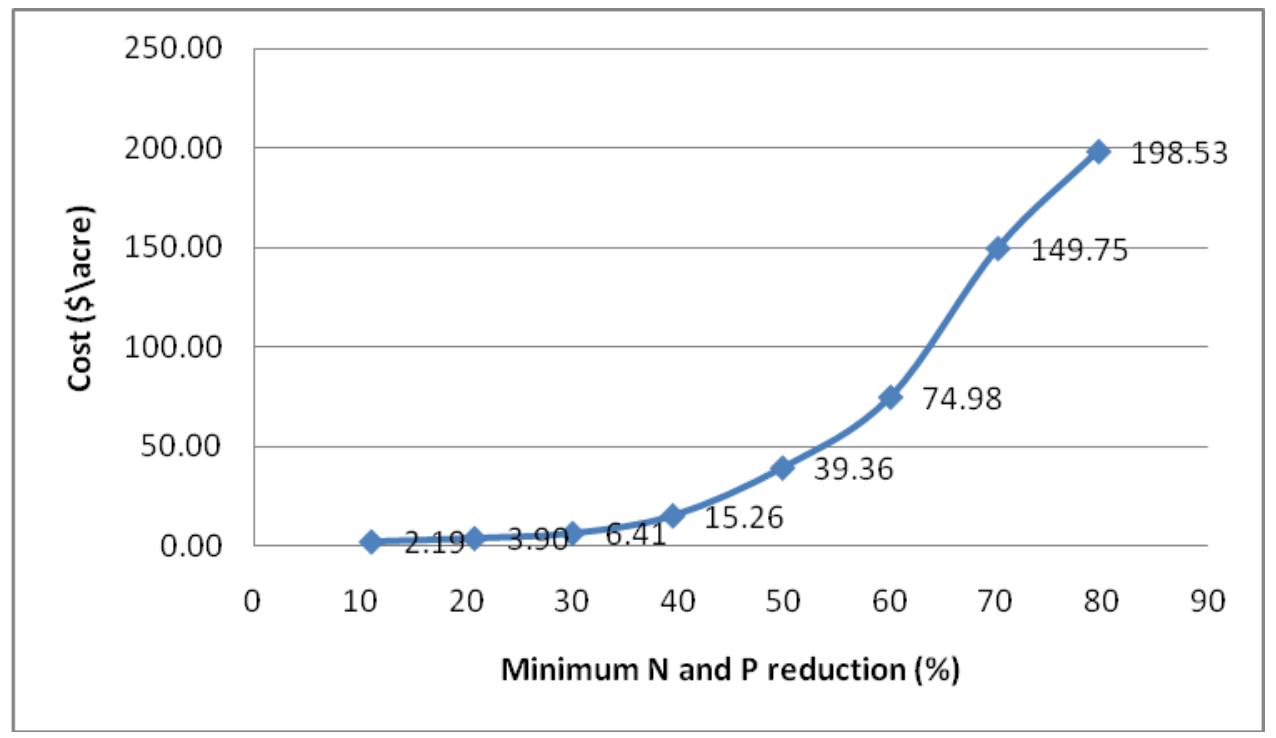

Figure 3: Per acre average costs of abatement actions needed to achieve equal percent reductions in $\mathbf{N}$ and $P$ 


\section{Table 1: Evolutionary Algorithm Results: Comparison of an Initial Seed with a Pareto Superior Individual}

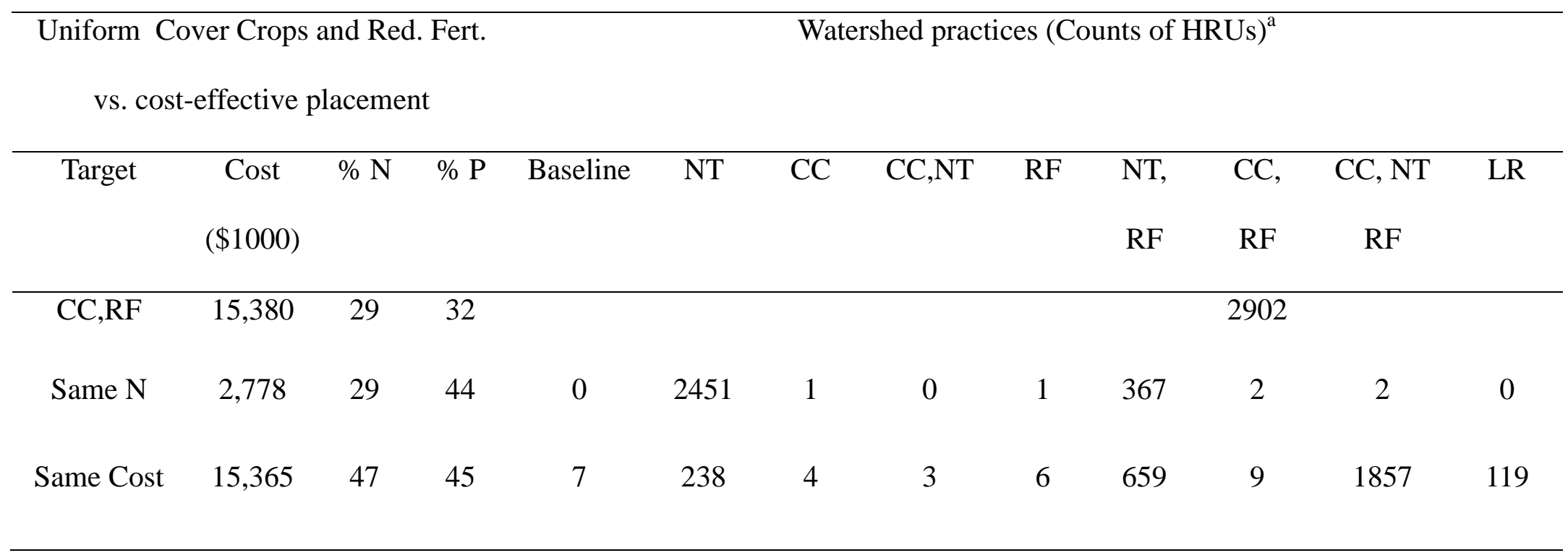

a. $\quad \mathrm{CC}=$ cover crops, $\mathrm{RF}=$ reduced fertilizer, $\mathrm{NT}=$ no till, $\mathrm{LR}=$ land retirement. 
Table 2: Least Cost Watershed Configurations to Simultaneously Obtain at least Uniform Percentage Reductions in N and $\mathbf{P}$

\begin{tabular}{|c|c|c|c|c|c|c|c|c|c|c|c|c|c|}
\hline \multirow{3}{*}{$\begin{array}{c}\% \\
\text { Decline } \\
\text { in } \mathrm{N}\end{array}$} & \multicolumn{2}{|c|}{ Cost } & \multicolumn{2}{|c|}{ Reduction } & \multicolumn{9}{|c|}{ Watershed practices (counts of HRUs) } \\
\hline & \multicolumn{13}{|c|}{$(\%)$} \\
\hline & $(\$ 1,000)$ & (\$/acre) & $\mathrm{N}$ & $\mathrm{P}$ & Baseline & No & Cover & $\mathrm{CC}$ & Reduced & NT, & $\mathrm{CC}$, & $\mathrm{CC}$ & Retire \\
\hline and $\mathrm{P}$ & & & & & & till & Crop & NT & Fert. & $\mathrm{RF}$ & $\mathrm{RF}$ & NT, RF & Land \\
\hline 10 & 1,158 & 2.19 & 11 & 21 & 1781 & 795 & 4 & 0 & 2 & 311 & 3 & 4 & 2 \\
\hline 20 & 2,064 & 3.90 & 21 & 33 & 580 & 2310 & 4 & 2 & 1 & 1 & 2 & 0 & 2 \\
\hline 30 & 3,389 & 6.41 & 30 & 44 & 1 & 2398 & 1 & 3 & 3 & 382 & 5 & 107 & 2 \\
\hline 40 & 8,072 & 15.26 & 40 & 45 & 7 & 9 & 4 & 90 & 3 & 2173 & 5 & 608 & 3 \\
\hline 50 & 20,815 & 39.36 & 50 & 50 & 5 & 10 & 5 & 11 & 12 & 966 & 11 & 1635 & 247 \\
\hline 60 & 39,651 & 74.98 & 60 & 60 & 6 & 3 & 5 & 3 & 9 & 213 & 8 & 1828 & 827 \\
\hline 70 & 79,194 & 149.75 & 70 & 81 & 4 & 61 & 2 & 369 & 2 & 417 & 5 & 3 & 2039 \\
\hline 80 & 104,993 & 198.53 & 80 & 89 & 4 & 8 & 3 & 91 & 7 & 1 & 6 & 2 & 2780 \\
\hline
\end{tabular}




\section{Endnotes}

${ }^{1}$ National surveys are planned or underway to provide information on rivers and wetlands. Data were being collected in the summers of 2008-2009 to provide information on the health of the nation's rivers and a report on the health of the nation's wetlands is due in 2011 (http://www.epa.gov/owow/monitoring/nationalsurveys.html ).

${ }^{2}$ The spatial aspect of agricultural emissions is sometimes considered part of the nonpoint source nature (see Lankoski, Lichtenberg and Ollikainen 2008.).

${ }^{3}$ Even total maximum daily loads (TMDLs) do not provide an enforceable standard. When water bodies are impaired the state is required to establish a TMDL which identifies the sources of the impairment and identifies reductions needed to remove the impairment. (Ironically, one could argue that a properly done TMDL requires solving the fundamental nonpoint source problem). However, a TMDL does not impose a requirement that emissions be reduced or water quality improved. An "implementation plan," typically outlining voluntary adoption of conservation practices, may be produced during or after the TMDL process.

${ }^{4}$ See discussion in Zitler, Laumanns and Thiele (2001).

${ }^{5} \mathrm{Mr}$. Charles Kiepe drove the watershed and recorded the land use, crop rotation, tillage practice, and other conservation actions on a table PC for each field (common land unit) in the watershed. Details are provided in Gassman (2008).

${ }^{6}$ Following Rabotyagov, corn yield response curves to fertilizer from Sawyer et al (2006) combined with the five year average corn price of $\$ 3.08 / \mathrm{bu}$ were used to estimate reduced profits from reduced fertilizer (\$4.06/acre mean, \$3.60 st. dev.). Likewise, 
county average cash rental rates (\$206 mean, \$24 st. dev.) were used to estimate the opportunity cost of retiring land at the field scale via correlations with the CSR value.

${ }^{7}$ Based on data from IFIPs, a cost of $\$ 4.09 /$ acre was assigned to each field for no-till and the cost of $\$ 25 /$ acre for cover crops was assigned based on cost of crop production estimates.

${ }^{8}$ See Rabotyagov et al. (2010) for details describing the SPEA2 algorithm implemented with GALib and i_SWAT.

${ }^{9}$ There is no guarantee that this frontier is the fully optimal frontier; further generations would likely result in additional individuals that would pareto dominate some of these individuals. Previous experience suggests that while additional improvements would continue to occur, this number of generations provides a reasonable representation adequate for the illustrative purposes intended here.

${ }^{10}$ It would of course be possible to construct separate supply schedules for each nutrient alone, without regard for the level of reduction of the other. The latter curves would more closely correspond to standard supply schedules. 
Iowa State University does not discriminate on the basis of race, color, age, religion, national origin, sexual orientation, gender identity, sex, marital status, disability, or status as a U.S. veteran. Inquiries can be directed to the Director of Equal Opportunity and Diversity, 3680 Beardshear Hall, (515) 294-7612. 